\title{
Medición del dolor en las punciones tras la aplicación de un método anestésico
}

\author{
$M^{a}$ del Mar Andrés Vázquez, Thais Castellanos Carrón, Enrique Gruss Vergara, Ma Carmen Gálvez \\ Serrano, José Guerrero Carrillo, Alicia González Horna
}

Fundación Renal Íñigo Álvarez de Toledo (FRIAT). Los Llanos. Móstoles. Madrid

\section{Introducción:}

La piel, el órgano más extenso, es la primera línea de defensa del organismo, protectora frente al medio externo. ${ }^{1}$ El dolor es una sensación subjetiva de malestar originado como resultado de estimulaciones nocivas de receptores sensoriales de la piel. ${ }^{2}$ La teoría de la compuerta explica los fenómenos relacionados con el dolor, sugiriendo que hay un sistema que bloquea las vías del dolor cuando el cerebro experimenta una sensación de distracción. ${ }^{3}$ La enfermería juega un papel fundamental con sus cuidados en el control del dolor de algunas de las técnicas que llevan a cabo tales como la punción de FAVIs, motivo que provoca ansiedad y malestar en muchos casos de pacientes en programa de hemodiálisis. ${ }^{4}$ HIPÓTESIS Las punciones en la FAVI con agujas congeladas a $-8^{\circ} \mathrm{C}$ y la aplicación de cloretilo como anestésico local disminuyen en cierta medida el nivel de dolor respecto a la punción con agujas a temperatura ambiente y sin anestésico tópico.

\section{Palabras clave:}

Fistula arteriovenosa, dolor, aguja congelada, cloretilo.

\section{Objetivos:}

1. Comparar el nivel de dolor que experimenta el paciente cuando se punciona la FAVI con agujas congeladas o con cloretilo, respecto a cuándo no se punciona con ninguna técnica especial.

2. Conseguir un método de punción efectivo, sin dolor, de fácil acceso y al bajo coste.

\section{Pacientes y método:}

Se estudiaron un total de 33 pacientes durante nueve sesiones, en tres semanas consecutivas. La medición del dolor tras la punción se realizó con las escalas EVA y Analógica Visual ${ }^{5}$. Previamente les explicamos el procedimiento y les pedimos que firmaran una autorización para el manejo de sus datos. Durante todo el periodo, el personal de enfermería y el grupo de pacientes a los que puncionaba, no varió. Se excluyeron pacientes con catéter, dificultad cognitiva y problemas de comunicación debido al idioma. Los criterios de inclusión fueron: tener una FAVI o injerto, realizar dos punciones en cada sesión y que no llevaran ningún tipo de analgésico aplicado. Estudio observacional prospectivo relacionando el dolor de la punción de FAVIs con el tipo de analgesia y las características del paciente. Se realizó la prueba de T-student para variables cuantitativas en dos muestras y test de Anova para más de tres muestras.

\section{Variables:}

Analgesia tópica, sexo, edad, DM y localización de la punción (arterial o venosa).

\section{Resultados:}

En función de los resultados obtenidos hemos podido demostrar que la DM, sexo y la edad no se relacionan con tener o no dolor, pero sin embargo la localización de la punción si es estadísticamente significativa aplicando o no un anestésico, percibiendo como más dolorosa la punción arterial en ambos casos. 


\section{Referencias Bibliográficas}

1. Revista de la Sociedad Española de Enfermería Nefrológica. ISSN 1139-1375; v.7n.2 Madrid abr.jun. 2004.

2. Santiago García-Velasco-Morago. Revista Metas de enfermería. "Reducción del dolor de las punciones vasculares. Una intervención enfermera". 01/06/2007.
3. Wilmar Eduardo Herrera. Teoría de la compuerta.14/02/2006.

4. Isabel Granados Navarrete, Dolores Abril Sabater. Revista de la sociedad Española de Enfermería Nefrológica "Una actuación de enfermería: intentar aliviar el dolor en las punciones de hemodialisis" 2005,8 (3).

5. www.guiasalud.es/egpc/cuidadospaliativos/.../ Anexo2_Escalas.pdf. 